\title{
HEART MRI IMAGES ANALYSIS IN CASE OF ARRYTHMOGENIC RIGHT VENTRICULAR CARDIOMYOPATHY (ARVC)
}

\author{
Sriyatun, Gando Sari, Nursama Heru Apriantoro \\ Jurusan Teknik Radiodiagnostik dan Radioterapi, Politeknik Kemenkes Jakarta II \\ Jln. Hang Jebat III F3 Kebayoran Baru DKI Jakarta, Kode Pos 12120 \\ Email : tutunsriyatun@gmail.com
}

\begin{abstract}
Arrhythmogenic Right Ventricular Cardiomyopathy (ARVC) is a cause of sudden cardiac death in otherwise healthy young adults. (ARVD/C) is an inherited cardiomyopathy characterized by lifethreatening ventricular arrhythmias and slowly progressive ventricular dysfunction. To diagnose ARVC is indicated by the Task Force of ARVC criteria in 1994 and then revised in 2010 set by the WHO/ISFC. To identify clinical characterictics of ARVC using CMR. The design of this study was qualitative descriptive, which was done by observational method using MRI 1.5 Tesla. The subject was an adult patient who did Cardiac MRI examination in National Cardiovascular Centre Harapan Kita on March 2018. The collected data were diagnostic images of CMR sequence. Then, it compared with diagnostic criteria of ARVC which was indicated by Task Force. The result of this study of several ARVC diagnostic criterias in Cardiac MRI examination with T1 Black Blood sequence is clear and accurate in indicating the presence of fat infiltration, CINE sequence is clear in visualizing the dilatation in the right ventricle, wall motion abnormalities, accordion sign, bulging, and LGE clearly shows fibrosis. The detection of right ventricular enlargement, fatty infiltration, fibrosis, and wall motion abnormalities in CMR is useful in the diagnosis of ARVC.
\end{abstract}

Keywords: Arrythmogenic Right Ventricular Cardiomyopathy, Arrythmia, CMR, Diagnosis, Task Force Criteria 2010

\section{ANALISIS CITRA MRI JANTUNG PADA KASUS ARRYTHMOGENIC RIGHT VENTRICULAR CARDIOMYOPATHY (ARVC)}

\begin{abstract}
ABSTRAK
Arrythmogenic Right Ventricular Cardiomyopathy (ARVC) merupakan salah satu penyebab kematian mendadak yang sering ditemukan, termasuk pada orang dewasa yang sehat. ARVC merupakan turunan dari Cardiomyopathy yang ditandai dengan ancaman Aritmia Ventricle dan tidak berfungsinya Ventricle secara perlahan. Untuk diagnosis ARVC berpedoman pada Kriteria Task Force tahun 1994 kemudian direvisi pada tahun 2010 yang ditetapkan oleh WHO/ISFC. Tujuan penetilian ini untuk mengidentifikasi kriteria klinis Arrythmogenic Right Ventricular Cardiomyopathy (ARVC) menggunakan CMR (Cardiac Magnetic Resonance). Desain penelitian ini adalah kualitatif deskriptif dengan pendekatan observasional menggunakan MRI 1,5 Tesla. Subjek penelitian adalah pasien dewasa yang melakukan pemeriksaan MRI Jantung di RS Jantung dan Pembuluh Darah Harapan Kita pada bulan Maret 2018. Data yang dikumpulkan berupa citra diagnostik CMR dari sequence yang ditetapkan, lalu dibandingkan dengan kriteria diagnostik ARVC berdasarkan Task Force. Hasil penelitian ini dari beberapa kriteria diagnostik ARVC pada pemeriksaan MRI Jantung dengan sequence T1 Black Blood cukup jelas dalam menunjukkan adanya infiltrasi lemak, sequence CINE cukup jelas dalam memvisualisasikan dilatasi pada Right Ventricle, kelainan gerakan dinding Jantung, dinding Jantung yang bergerigi (Accordion Sign), Penonjolan (Bulging) serta Late Gadolinium Enhancement (LGE) cukup jelas memperlihatkan Fibrosis. Deteksi pembesaran Right Ventricle, infiltrasi lemak, Fibrosis, dan ketidaknormalan pergerakan dinding Jantung dengan MRI sangat akurat untuk diagnosis ARVC.
\end{abstract}

Kata kunci: Arrythmogenic Right Ventricular Cardiomyopathy, Aritmia, CMR, Diagnosis, Kriteria Task Force 2010 


\section{PENDAHULUAN}

Arrhythmogenic Right Ventricular Cardiomyopathy (ARVC), atau juga sering dikenal dengan Arrhythmogenic Right Ventricular Dysplasia (ARVD) dicirikan dengan pergantian otot Jantung pada RV (Myocardial Right Ventricle) oleh jaringan lemak atau jaringan Fibrosa (Fibrofatty).(1.2.3). ARVC dijelaskan dengan gagal Jantung, Tachycardia pada Ventricle, dan umumnya kematian Jantung mendadak pada populasi orang usia muda. Patogenesis ARVC tidak sepenuhnya berkembang, namun hal tersebut tampak pada mayoritas pasien. Prevalensi populasi diperkirakan terjadi pada sekitar 1 dari 5000 orang.(3.4)

Pada Right Ventricle pasien yang terindikasi ARVC mengalami kontraksi otot Jantung yang buruk akibatnya kemampuan Jantung untuk memompa darah melemah (5). Penyebab ARVC belum diketahui sepenuhnya, namun yang paling banyak terjadi pada pasien merupakan faktor genetik. Pada dasarnya, karateristik pasien ARVC terindikasi diabetes, hipertensi, hiperlipidemia, serta penyakit ginjal kronis. Gejala ARVC yang biasa terjadi adalah Jantung berdebar - debar, mudah lelah, kehilangan kesadaran, dan nyeri dada (6.7.8).

Visualisasi ketidaknormalan struktur dan fungsi RV merupakan salah satu kriteria diagnostik ARVC (9.10). Modalitas noninvasif yang sering digunakan seperti Echocardiography 2 Dimensi terbatas pada evaluasi volume dan fungsi RV, dikarenakan RV memiliki geometri yang kompleks. Angiocardiography menyediakan informasi mengenai fungsi RV regional dan global, namun modalitas tersebut adalah teknik invasif. Pada penggunaan modalitas CT-Scan informasi yang didapat terbatas, namun dapat digunakan bagi pasien yang terpasang implant defibrillator untuk mendeteksi morfologi dan pergerakan dinding Jantung. Magnetic Resonance Imaging menggambarkan morfologi dan evaluasi fungsi yang akurat untuk RV tanpa perubahan geometri. Deteksi lemak Intramyocardial dan Fibrosis RV sangat baik karena kegunaan MRI yang luar biasa untuk karakteristik jaringan (11.12.13.14) 


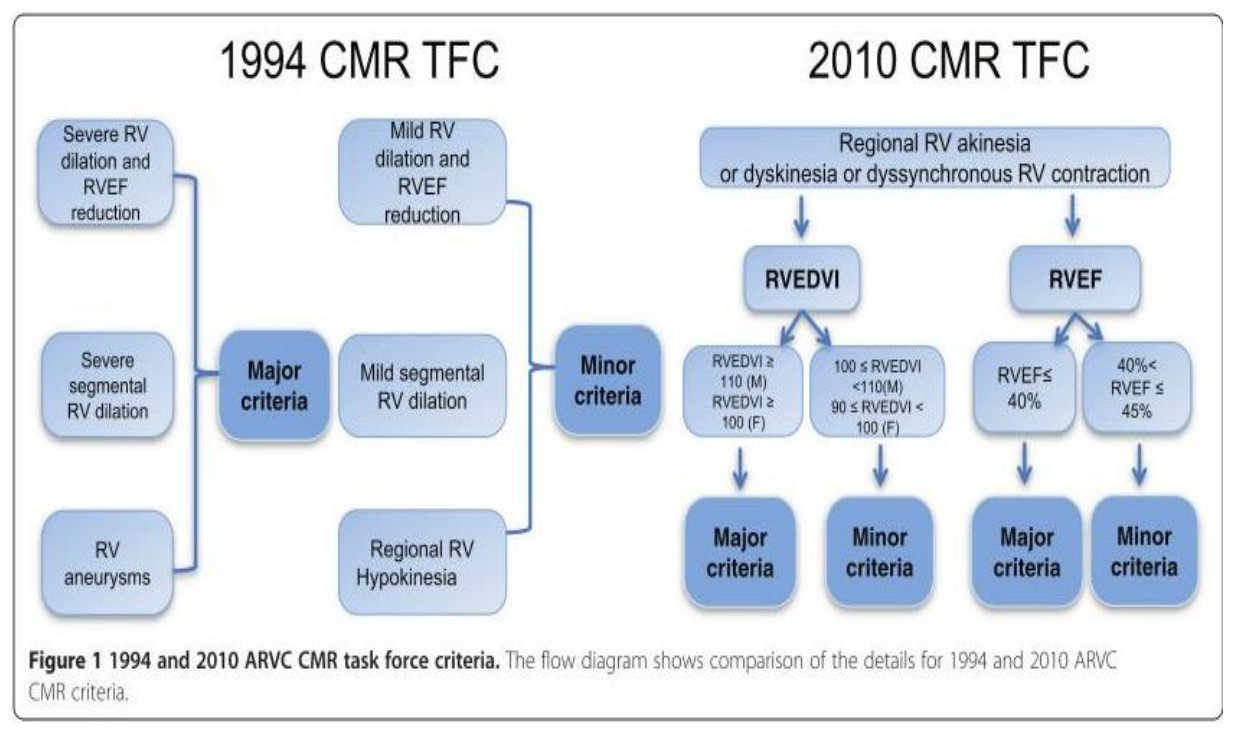

Gambar 1 Kriteria Task Force CMR ARVC. Diagram ini menunjukkan detail perbandingan kriteria Task Force tahun 1994 dan tahun 2010 (5)

Berdasarkan Kriteria Task Force ARVC yang asli pada tahun 1994, klinis ARVC ditinjau dari struktural, histologi, ECG, aritmia, serta riwayat penyakit keluarga (5.13.15) Revisi Kriteria Task Force ARVC tahun 2010 lebih spesifik untuk tingkat diagnosis. Isi Kriteria Task Force ARVC tahun 2010disusun sebagai sistem score dengan kriteria mayor dan kriteria minor yang termasuk struktur dan fungsi Ventricle yang lemah, karateristik kelainan depolarisasi, karateristik kelainan repolarisasi, jenis aritmia pada Ventricle, hasil biopsy Cardiac, riwayat penyakit keluarga, serta dilakukan pemeriksaan genetik (16.6.8.17). Kriteria diagnostik klinis ARVC yaitu adanya infiltrasi lemak pada Right
Ventricle, kelainan gerakan dinding jantung dengan dan tanpa dilatasi, terdapat aneurisma, dinding Right Ventricle bergerigi (Accordion Sign) dan terdapat penonojolan (bulging), persentasi, kemampuan pompa jantung $(2.17 .18 .19 .20)$

\section{METODE PENELITIAN}

Penelitian ini merupakan penelitian yang dilakukan secara observasional menggunakan MRI Philips Achieva 1,5 Tesla. Populasi dari penelitian ini adalah semua pasien yang melakukan pemeriksaan MRI Cardiac kategori dewasa, dengan sampel yaitu pasien dengan klinis ARVC di RS Jantung dan Pembuluh Darah Harapan Kita pada bulan Maret 2018. Data yang 
dikumpulkan berupa citra diagnostik

CMR dari sequence yang ditetapkan, lalu dibandingkan dengan kriteria diagnostik ARVC berdasarkan Task Force pada gambar 1 .

Persiapan umum yang harus dilakukan sebelum pemeriksaan MRI Jantung, yaitu pasien berpuasa kurang lebih 8 jam sebelum pemeriksaan untuk mencegah terjadinya reaksi negatif yang ditimbulkan oleh kontras media atau oleh Adenosine terhadap sistem metabolisme tubuh. Pasien dilarang untuk mengonsumsi minuman atau makanan yang mengandung kafein (kopi, teh, coklat) sebelum pemeriksaan, karena kafein dapat memacu Jantung untuk bekerja keras (meningkatkan nilai Heart Rate). Menunda untuk tidak minum obatobatan yang terkait dengan Jantung dan pembuluh darah. Cek Ureum Creatinin. Pastikan Glomerulus Filtration Rate $(\mathrm{GFR})>30$.

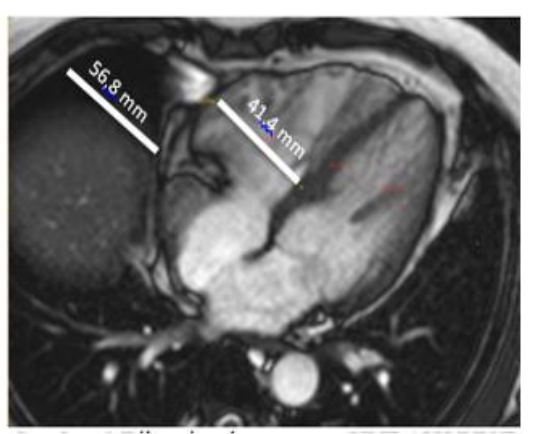

(a)
Alat dan bahan yang digunakan pada pemeriksaan MRI Cardiac Contrast, yaitu pesawat MRI Philips Achieva 1.5 Tesla, Sense Body Coil, ECG Gating, Respiratory Triggering, Blood Pressure, Automatic Contrast Injector, Syringe Pump, Adenosine Tri Phosphate, Spuit dan Y-Connector, Intravenous Cath nomor 20-22 gauge, kontras media Gadovist dengan dosis 0,05-0,1 mmol/KgBB, serta cairan saline.

Pasien dijelaskan prosedur pemeriksaan beserta tahapan-tahapan dan risiko yang akan terjadi selama pemeriksaan oleh Cardiolog. Pasien wajib mengisi inform consent atau surat persetujuan dilakukan tindakan dan mengisi lembar screening safety MRI. Cardiolog juga melakukan anamnesa tentang keluhan, indikasi klinis, riwayat penyakit dan hasil pemeriksaan sebelumnya. Kemudian dilakukan perekaman ECG 12 lead oleh perawat

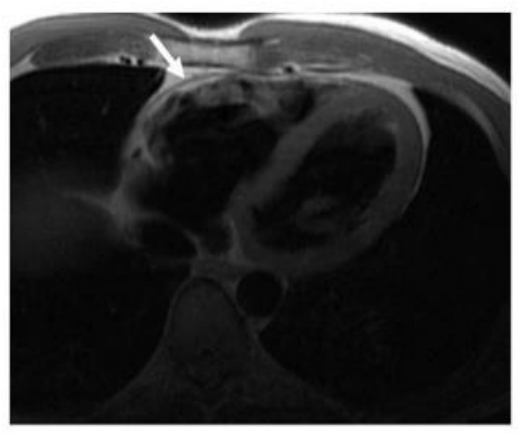

(b)

Gambar 2 Sequence CINE 4CH REST dan sequence T1 Black Blood 
atau Cardiolog serta pemasangan intravenous line. Kemudian pasien dipastikan untuk buang air kecil sebelum pemeriksaan mengingat waktu pemeriksaan yang lama (>30 menit). Kemudian pasien diperiksa sesuai SOP di RSJPDHK dengan MRI 1.5 T seperti yang telah dijelaskan sebelumnya pada prosedur pemeriksaan.

\section{HASIL DAN PEMBAHASAN}

Berdasarkan observasi penulis di RSJPDHK terkait prosedur pemeriksaan yang dilakukan adalah pemeriksaan MRI Jantung dilakukan dengan satu sampel pasien, yaitu Tn. Y berusia 39 tahun, dengan diagnosis ARVC. Hasil pemeriksaan MRI Jantung terdiri atas gambar dan CINE yang diambil dari beberapa metode dan sequence. Tiaptiap sequence memberikan informasi yang khas. Sequence pemeriksaan MRI yang diperlukan yaitu T1 Darkblood Axial dan T1 SPIR TSE Axial, Steady State Free Precession (SSFP) Fase Rest yang dapat dilihat dari $\mathrm{R} 2 \mathrm{CH}$ View dan 4CH View, dan Late Gadolinium Enhancement (LGE) yang dilihat dari Short Axis View. Analisis gambaran MRI Cardiac yang terindikasi ARVC, yaitu sebagai berikut :

Pada gambar 2 :

a) Chamber MRI Cardiac, terjadi dilatasi pada Right Ventricle (56,8 $\mathrm{mm}$ ) dengan ditandai dengan ukuran RV lebih besar daripada Left Ventricle (41,4 $\mathrm{mm})$.

b) T1 Black Blood, sequence ini baik untuk mengevaluasi anatomi dan morfologi ruang Jantung, struktur Vascular dan Pericardium. Hasil gambaran anatomi darah berwarna

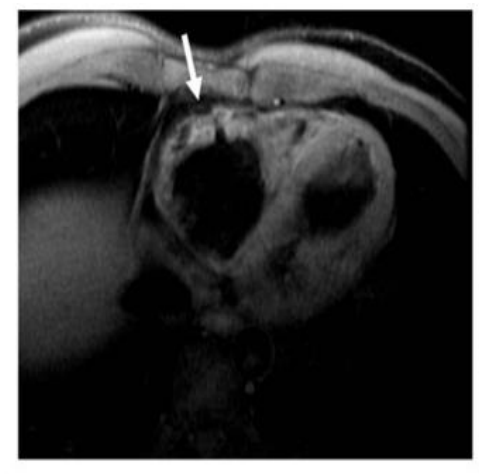

(a)

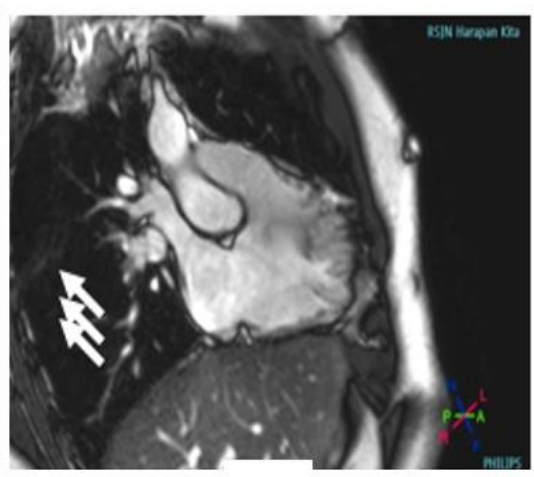

(b)

Gambar 3 sequence T1w dan Accordion Sign sequence CINE R2CH REST 
hitam sementara lemak berwarna putih dengan menggunakan Double Inversion Recovery. Terlihat gambaran infiltrasi lemak pada Myocardial Right Ventricle yang hyperintense, reference by fat yang juga berwana putih (hyperintense).

Pada Gambar 3 :

a) T1w SPIR, digunakan untuk melihat infiltrasi lemak, pada sequence ini lemak akan berwarna hyperintens

b) Pada sequence CINE R2CH akan tampak gambaran RV yang bergerigi, oleh karena itu, gambaran sering disebut sebagai Accordion Sign.

Pada Gambar 4:

a) Gambaran yang terdapat kriteria diagnostik ARVC, salah satunya terdapat penonjolan (bulging) pada
RV

b) Jantung yang terindikasi ARVC telah menunjukkan beberapa ciri khas pada tiap sequence, kriteria diagnostik ARVC yang terakhir adalah terdapatnya Fibrosis pada sequence Late Gadolinium Enhancement (LGE).

\section{SIMPULAN}

Arrhythmogenic Right Ventricular Cardiomyopathy (ARVC), atau juga sering dikenal dengan Arrhythmogenic Right Ventricular Dysplasia (ARVD) dicirikan dengan pergantian otot Jantung pada RV (Myocardial Right Ventricle) oleh jaringan lemak atau jaringan Fibrosa (Fibrofatty). Deteksi pembesaran Right Ventricle dapat dievaluasi dengan sequence $\mathrm{CINE} 4 \mathrm{CH}$, infiltrasi lemak yang dapat dievaluasi menggunakan sequence T1 Darkblood

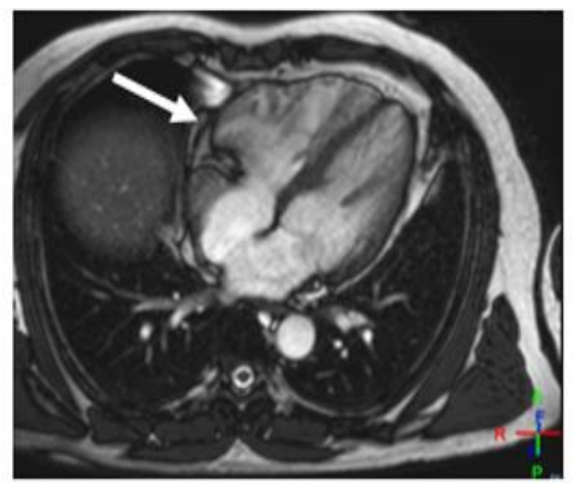

(a)

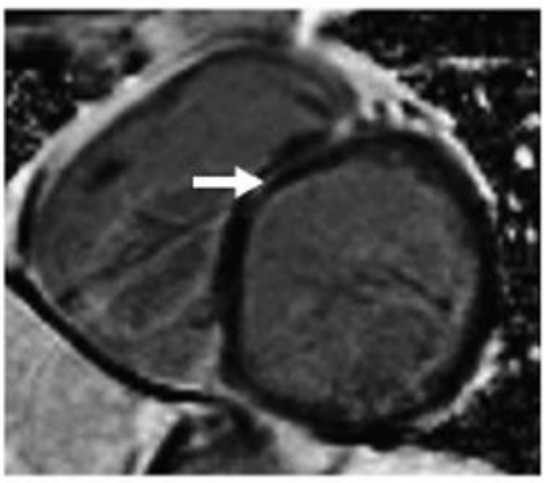

(b)

Gambar 4. sequence CINE 4CH REST dan sequence Late Gadolinium Enhancement (LGE) 
Axial dan T1 SPIR Axial, sequence Late

Gadolinium Enhancement yang dapat memvisualisasikan Fibrosis, ketidak normalan pergerakan dinding Jantung serta Accordion Sign yang dapat diidentifikasi dengan CINE R2CH dan 4CH. MRI Jantung sangat akurat untuk diagnosis ARVC. Hasil kriteria gambaran yang dihasilkan sesuai dengan kriteria Task Force CMR untuk ARVC.

\section{DAFTAR PUSTAKA}

1. Goetschalckx, K., Rademakers, F., \& Bogaert, J. (2010). Right ventricular function by MRI. Current Opinion in Cardiology. https://doi.org/10.1097/HCO.0b013 e32833b78e6

2. Rastegar, N., James, C. A., Murray, B., Tichnell, C., Calkins, H., \& Zimmerman, S. L. (2016). Fibrofatty Changes: Incidence at Cardiac MR Imaging in Patients with Arrhythmogenic Right Ventricular. RSNA, O(0), 1-8.

3. Murphy, D. T., Shine, S. C., Cradock, A., Galvin, J. M., Keelan, E. T., \& Murray, J. G. (2010). Cardiac MRI in arrhythmogenic right ventricular cardiomyopathy. American Journal of Roentgenology, 194(4), 299-307. https://doi.org/10.2214/AJR.09.345 0

4. James, C. A., \& Calkins, H. (2013). Update on Arrhythmogenic Right Ventricular Dysplasia / Cardiomyopathy ( ARVD / C ). Springer Science+Business Media New York, 476-487. https://doi.org/10.1007/s11936-

013-0251-8

5. Liu, T., Pursnani, A., Sharma, U. C., Vorasettakarnkij, Y., Verdini, D., Deeprasertkul, P., ... Ghoshhajra, B. B. (2014). Effect of the 2010 task force criteria on reclassification of cardiovascular magnetic resonance criteria for arrhythmogenic right ventricular cardiomyopathy. Journal of Cardiovascular Magnetic Resonance, 1-10.

6. Marcus, F. I., Abidov, A., \& D, P. (2012). Arrhythmogenic Right Ventricular Cardiomyopathy 2012: Diagnostic Challenges and Treatment. Journal of Cardiovascular Electrophysiology, 1-5. https://doi.org/10.1111/j.15408167.2012.02412.x

7. Pfluger, H. B., Phrommintikul, A., Mariani, J. A., Cherayath, J. G., Amit, D., \& Taylor, A. J. (2008). Utility of Myocardial Fibrosis and Fatty Infiltration Detected by Cardiac Magnetic Resonance Imaging in the Diagnosis of Arrhythmogenic Right Ventricular Dysplasia - A Single Centre Experience. Elsevier Inc., 478-483. https://doi.org/10.1016/j.hlc.2008.0 3.085

8. Steckman, D. A., Schneider, P. M., Schuller, J. L., Aleong, R. G., Nguyen, D. T., Sinagra, G., ... Sauer, W. H. (2012). Utility of Cardiac Magnetic Resonance Imaging to Differentiate Cardiac Sarcoidosis from Arrhythmogenic Right Ventricular Cardiomyopathy. AJC, 110(4), 575-579. https://doi.org/10.1016/j.amjcard.20 12.04.029

9. Maisch, B., \& Noutsias, M. (2012). $\mathrm{C}$ a rdi o $\mathrm{m}$ y o p a $\mathrm{th}$ i e $\mathrm{s}$ : Classification, Diagnosis, and Treatment. Heart Failure Clinics, 
8(1), 53-78.

https://doi.org/10.1016/j.hfc.2011.0 8.014

10. Mayosi, B. M., Fish, M., Shaboodien, G., Mastantuono, E., Kraus, S., Wieland, T., ... Crotti, L. (2017). Identification of Cadherin 2 (CDH2) Mutations in Arrhythmogenic Right Ventricular Cardiomyopathy. American Heart Association, 2.

11. Marcus, F. I., Co-chair, W. J. M., Sherrill, D., Basso, C., Bauce, B., Bluemke, D. A., ... Zareba, W. (2010). Diagnosis of arrhythmogenic right ventricular cardiomyopathy / dysplasia Proposed Modification of the Task Force Criteria. European Heart Journal, 121(13), 806-814.

12. Migrino, R. Q., Sosnovik, D. E., Leichter, J. A., \& Brady, T. J. (2004). Value of Fat Suppression in the MRI Evaluation of Suspected. American Roentgen Ray Society, (March), 587-592

13. Tandri, H., Uk, M. R. C. P., Calkins, H., Nasir, K., Bomma, C., Castillo, E., ... Ao, J. O. (2003). Magnetic Resonance Imaging Findings in Patients Meeting Task Force Criteria for Arrhythmogenic Right Ventricular Dysplasia. Division of Cardiology and *Department of Radiology, 143(March), 476-482.

14. Tandri, H., Macedo, R., Calkins, H., Marcus, F., \& Cannom, D. (2008). Imaging and Diagnostic Testing Role of magnetic resonance imaging in arrhythmogenic right ventricular dysplasia: Insights from the North American arrhythmogenic right ventricular dysplasia ( ARVD / C ) study. Mosby, Inc., 143.

15. Capulzini, L., Brugada, P., Brugada, J., \& Brugada, R. (2010).
Arrhythmia and Right Heart Disease: From Genetic Basis to Clinical Practice. Rev Esp Cardiol, 63(8), 963-983.

16. Jain, A., Tandri, H., Calkins, H., \& Bluemke, D. A. (2008). Journal of Cardiovascular Magnetic Role of cardiovascular magnetic resonance imaging in arrhythmogenic right ventricular dysplasia. Journal of Cardiovascular Magnetic Resonance, 14, 1-14.

17. T, C. B., \& Thiene, G. (2005). Adipositas cordis, fatty infiltration of the right ventricle, and arrhythmogenic right ventricular cardiomyopathy . Just a matter of fat? B. Elsevier Inc., 14, 37-41. https://doi.org/10.1016/j.carpath.20 04.12.001

18. Macedo, R., Prakasa, K., Tichnell, C., Marcus, F., Calkins, H., Lima, J. A. C., .. Tichnell, C. (2007). Marked Lipomatous Infiltration of the Right Ventricle: MRI Findings in Relation to Arrhythmogenic Right Ventricular Dysplasia. American Journal of Roentgenology, (May), 423-428.

19. Xu, H., Chen, J., Yang, Z., \& Li, R. (2017). Early Marker of Regional Left Ventricular Deformation in Patients With Hypertrophic Cardiomyopathy Evaluated by MRI Tissue Tracking: The Effects of Myocardial Hypertrophy and Fibrosis. International Society for Magnetic Resonance in Medicine, $1-9$.

20. Leong, D. P., Madsen, P. L., \& Selvanayagam, J. B. (2016). Noninvasive evaluation of myocardial fibrosis: implications for the clinician. Group.bmj.com. 